\title{
Involvement of Civil Society Organization in Facilitating the Implementation of Ten Steps for Successful Breastfeeding: Analysis of Health Care Workers' Perspectives?
}

\author{
Pande Putu JANURAgA ${ }^{1}$, Edwina FrisdiantinY ${ }^{2}$, Yessi Crosita ${ }^{3}$, \\ Wahdini HAKIM ${ }^{4}$, Doddy IZWARDY ${ }^{5}$ and Aang SUTRISNA ${ }^{6, *}$ \\ ${ }^{1}$ Center for Public Health Innovation, Faculty of Medicine, Udayana University, Bali, Indonesia \\ ${ }^{2}$ Consultant for Save the Children Indonesia, Jakarta, Indonesia \\ ${ }^{3}$ Center for Public Health Innovation, Faculty of Medicine, Udayana University, Bali, Indonesia \\ ${ }^{4}$ Save the Children Indonesia, Jakarta, Indonesia \\ ${ }^{5}$ Direktorat Gizi Masyarakat, Kementerian Kesehatan Republik Indonesia, Jakarta, Indonesia \\ ${ }^{6}$ Consultant for the Global Alliance for Improved Nutrition (GAIN), Jakarta, Indonesia
}

(Received June 13, 2019)

\begin{abstract}
Summary Despite the present of national policy support, the prevalence of early breastfeeding initiation in Indonesia are still low. Research has shown that health care workers are the most reliable source for breastfeeding advice, but sadly they were often lacking in capacity. The aim of the study to assess the involvement of civil society organization (CSO) and its associated factors in facilitating the implementation of Ten Steps for Successful Breastfeeding (TSSB) based on health care workers' perspectives in Malang and Sidoarjo districts, East Java Province, Indonesia. We used qualitative approach to in-depth interview 117 participants and conducted 14 FGDs in Sidoarjo and Malang East Java. the PARiHS framework was used to identify the role of CSO in facilitating the BFHI implementation from the health workers perspective to offer insight on the facilitation process and development of future recommendations. The study found that the health care workers' have good knowledge on the benefits of breastfeeding with significant portion of the knowledge that they hold are coming from trainings provided by the CSO. There was cultural context barriers within the community, where grandmothers are considered as an important influence factor esspecially for working mothers. The implementation of training by the CSO was considered appropriate due to its ability to address some pressing structural obstacles and provide not only training to improve evidence but also help in addressing other contextual barriers. The CSO has offered opportunities not only for dissemination of evidence-based intervention but also to close gaps on resources provision to attend courses.
\end{abstract}

Key Words BFHI, ten steps for successful breastfeeding, barriers, facilitators

Breast milk given exclusively during the first six months of life is the optimal source of nutrition for infants growth as well as provides support for their immune system development (1) and this benefit is regardless of the socio-economic status (2). Estimated under- 5 deaths prevented by breastfeeding alone is 13\% of the total under 5 child mortality worldwide (3).Thus, as a mean to better nourish the future generation breastfeeding is considered as a smart economic investement (4) However, breastfeeding is often no longer the norm where there is a shift in socio cultural and market factors (5).

\footnotetext{
*To whom correspondence should be addressed.

E-mail: asutrisna@gainhealth.org

Abbreviations: Baduta, infant and young child under 24 mo; BFHI, Baby-friendly Hospital Initiative; CSO, Civil Society Organisation; EBP, Evidence Based Practice; GAIN, Global Alliance for Improved Nutrition; health care workers, health care workers; TSSB, Ten Steps for Successful Breastfeeding; UNICEF, United Nations Emergency Children's Fund; YSTC, Yayasan Sayangi Tunas Cilik.
}

Health care workers have a significant role to influence mother for breasfeeding trough contact within identified critical times, both before and after delivery (6) Hence, World Health Organization and UNICEF have developed the Baby-friendly Hospital Initiative (BFHI). $\mathrm{BFHI}$ is a global initiative that focuses on giving every baby the best start in life trough provision of health care environment that encourages breastfeeding (7) This multi components approach aims to support the implementation of the Ten Steps to Successful Breastfeeding (TSSB) (Table 1) as well as to end the distribution of free and low-cost supplies of breast milk substitutes to health facilities. The BFHI implementation in various countries has been proved to increase the coverage of exclusive breastfeeding $(8-10)$.

The implementation of TSSB in Indonesia is supported by the Ministry of Health decree number 450/ Menkes/SK/IV/2004 and later strengthen by the President Regulation number 33, year 2012 on exclusive breastfeeding. Despite the present of national policy support, the prevalence of early breastfeeding initia- 
Table 1. Ten Steps to Successful Breastfeeding.

Ten Steps to Successful Breastfeeding; Every facility providing maternity services and care for new-born infants should:

1. Have a written breastfeeding policy that is routinely communicated to all health care staff.

2. Train all health care staff in skills necessary to implement this policy.

3. Inform all pregnant women about the benefits and management of breastfeeding.

4. Help mothers initiate breastfeeding within half an hour of birth.

5. Show mothers how to breastfeed, and how to maintain lactation even if they should be separated from their infants.

6. Give new-born infants no food or drink other than breast milk, unless medically indicated.

7. Practise rooming-in - that is, allow mothers and infants to remain together $-24 \mathrm{~h}$ a day.

8. Encourage breastfeeding on demand.

9. Give no artificial teats or pacifiers (also called dummies or soothers) to breastfeeding infants.

10. Foster the establishment of breastfeeding support groups and refer mothers to them on discharge from the hospital or clinic.

tions and continuation of exclusive breastfeeding until six months in Indonesia are still low. The prevalence in 2016 were $42,7 \%, 9,2 \%$ and $29,5 \%$ respectively for under one hour of birth early breastfeeding initiation, after one hour initiation and exclusive breastfeeding until six month (11).

The success of TSSB implementation within the health care services largely depends on the health care workers as clinicians, administrator staffs and managers. Research has shown that in Indonesia, health care workers are the most reliable source for breastfeeding advice. However, they are not easily accessible and often provided inconsistent information (12). Therefore, training aiming to improve health care workers capacity is important. Most of the times, $20 \mathrm{~h}$ or $40 \mathrm{~h}$ certified training on exclusive breastfeeding for health workers is provided by local health authorities. However, the training could be conducted also by not for profit goverment organization, particularly Civil Society Organisation (13), altough sometimes it is also reffered as Community Based Organization (14).

Yayasan Sayangi Tunas Cilik (YSTC) Indonesian local partner of Save the Children (SAVE), a CSO, has trained managements and health care workers in 20 health care facilities in East Java Province to support the BFHI and TSSB implementation. Maternal, infant and young child nutrition (Baduta) project conducted by Save the Children and its Indonesian local partner YSTC aimed to constribute to the reduction of stunting amongs infant and young child under $24 \mathrm{mo}$ as well as to the improvement of maternal nutrition among pregnant and lactating women in East Java province. The interventions implemented in the Baduta project were based on result of formative study conducted by Global Alliance for Improved Nutrition (GAIN) in 2013. The project then applied the multifaceted interventions aiming at improving access to quality health care and nutritional services in two districts in East Java over the period of 36 mo (2014-2016) (15). Hence an examination of YSTC's role as CSO in enabling the TSSB trough BFHI in the area is needed. This paper aims to examine the role of CSO in facilitating the TSSB implementation from the health workers perspective.

Evaluation framework. Evaluating implementation of evidence-based practice means acknowledging the complex and diverse challenges it faces. Recent integrative review pointed the complexity of facilitators and barriers for adoption of TSSB which demands a more theory-driven studies to help formulate the most effective strategies for wider implementation of the BFHI (16) Against this background the Promoting Action on Research Implementation in Health Services (PARiHS) framework which highlights the nature of the evidence being used, the quality of context, and, the type of facilitation required to enable the change process is considered as the appropriate tool to evaluate TSSB implementation within the context of this study (17). The PARiHS has been used in the field of BFHI and TSSB di various countries $(18,19)$ and has yielded valuable insight for future recommendations.

In brief Successful Implementation (SI) based on revised PARiHS framework is a (f) unction of Evidence (E), Context (C), and Facilitation (F) $(17,20)$. The Evidence $(\mathrm{E})$ is implementable form of the research evidence as perceived by multiple stakeholders in this study it is defined as TSSB elements and implementations perceived by health care workers. The Context (C) is Contextual Readiness for targeted Evidence Based Practice (EBP) in this study it is defined as cultural, structural and leadership context surrounding TSSB implementation. The Facilitation (F) is interventions that facilitators and others employ to enhance adoption, in this study it is defined as the CBO role as facilitators as perceived by respondents. Each element can be assessed for whether its status is weak or strong. For Facilitation, the focus is on rating "appropriateness" for successful implementation judged from the uptake of TSSB by the health care facilities.

\section{METHODS}

A descriptive qualitative design was used to explore health workers' perceptions on the CSO's role in facilitating BFHI implementation. Purposive sampling was used to recruit participants from various health care facilities including Community Health Centre, Hospital, and private owned Maternity Health Care Service. Primary data gathered trough in-depth interviews and focus group dicussions. Respondents were managers as well as clinical staffs who provide maternity services at designated facilities (midwives and nurses). Leaders of the health facilities and head of the maternity services were considered as managers, 2-3 respondents per health facility were chosen to represent voices from 
Table 2. Detail on data collection conducted.

\begin{tabular}{lcc}
\hline Data Collection & \multicolumn{2}{c}{ Location } \\
\hline Managements & Sidoarjo & Malang \\
IDIs & 29 & 40 \\
FGD & 3 & 2 \\
\hline Clinical staff & Sidoarjo & Malang \\
IDIs & 23 & 25 \\
FGD & 4 & 5 \\
\hline
\end{tabular}

managerial level. While for clinical staffs, 2-3 persons were selected from each health facilities to voice their opinion. The number of respondents recruited is presented in Table 2.

Prior to data collection enumerators joined four days of training on data collection procedure designed for the research including field testing the instruments. Enumerators were also trained to uphold the two basic principles of anonymity and confidentiality in treating their interviewee. The data collection was focused on gathering information on how the evidence on breastfeeding practice was perceived by the health care workers? What were the obstacles faced by the health care workers in turning the evidence based knowledge and skill they have into practice? What were the roles of the CSO in facilitating the implementation as well as in addressing the identified barriers? Were there unintended consequences from the intervention?

Transcript data were analysed using deductive qualitative content analysis (21). Thematic matrix based on three main elements of the PARiHS framework (evidence, context, facilitation) was used to frame the categorization of the data and followed by implementation of inductive principles to generate categories and subcategories within each of the three main themes (22). To achieve this, transcripts were read multiple times to identify the main points that were addressed in the interviews and FGDs. Each transcript was then read line-by-line to generate codes related to the themes of evidence, context, and facilitation. Codes were subsequently synthesized into higher-level categories (19). These steps were done using NVIVO 11 soft ware.

\section{RESULTS}

\section{Knowledge and belief related to breastmilk}

Clinical staffs resoundingly described breast milk as "the best form of nutrition for infants" which also "provides added benefit in term of its practicality and price". In addition, it also "helps to restore mother's postpartum condition".

"The benefit of breast milk for baby is obvious for their immunity and of course it is cheaper. Because there is nothing better than breast milk, and then there are benefits for the mother's health because it prevents breast cancer and also improves the uterus contraction after birth."

Respondents from clinical staffs also highligted the importance of early breastfeeding initiation as a crucial step to ensure breastfeeding in which also provide benefits for both mother and child

"...for the baby, it is the bonding and also the warmth, while for the mother it helps with the release of placenta and breast milk"

Interestingly some respondents from clinical staffs went beyond knowledge understanding alone, they pointed out "their personal experience of failure to breastfeed as one of the main reasons to support the TSSB implementation in their workplace"

"I failed to exclusively breastfeed my first child; it hurts me so much. I felt disappointed, denials and always wanted to cry, like "why?" Now I know what happened, it was nipple confusion then pumped my breast milk and put it in a bottle, because my child did not directly suck my breast then the production went less and less. Because of that experience, I don't want any other mother to go through that like me"

In addition to the knowledge on benefits of breastfeeding and its early initiation, respondents both from clinical staffs also highlight the negative consequences of giving formula milk, teats and bottle feeding. Respondents also encouraged skin to skin contact, rooming in and breastfeeding on demand practices.

Furthermore, it was belief that commitment to implement TSSB largely depends on the staffs understanding on the importance of BF as well as having the appropriate skill to conduct the counselling

“...they need to truly understand the importance of early initiation of $\mathrm{BF}$, exclusive $\mathrm{BF}$, rooming in and other things related, because then they will feel guilty for not promoting it."

(Clinical staff)

Despite the positive views on breastfeeding and TSSB elements in general, participants' identified family belief about breastfeeding taboo such as the "grandmother factor", "myth about cracked nipples" and "perceived inadequacy of breast milk both in quantity and quality". Grandmothers are perceived as having a central role in supporting or preventing exclusive breastfeeding in various context one of it is where grandmothers also seen as having pivotal role for reproducing myth and taboo, as one of the clinical staffs elaborated

"The perception was it will kill the baby, it was from the grandmother who said when the nipples are cracked, and mothers should not breastfeed with no further explanations given. Then the mother obeyed thus she did not breastfeed her first child. For the second child, since she joined the antenatal class she was exposed to different perspectives. Now at least for this second child, she partially breastfeeds her baby, we need to appreciate that although it is not only breast milk" (Clinical staff)

Managers and clinical staffs both stated that the task to maintain breastfeeding is much more difficult than to start it, once the mothers are at home the family support is much more important than the health care 
workers

"...once they were discharged, they often lack of fammily support. The grandmothers ussually feel that they are more experienced and in the the past this is how they do it and all are well"

(Managers)

Sometimes the barrier to breastfeed can come from the mothers themselves

"Usually formula milk was given to the baby when they are already at home and then the frequency of breastfeeding is decreasing then the mother feels that she doesn't produce enough milk. That is often the case"

(Clinical staff)

The challenges are even bigger for young working mother

"When they go home, the mothers go back to work and the babies are in the care of the grandmothers and the only thing that the grandmothers care about is to make the baby not crying which mean to give bottled milk"

(Clinical staffs)

Time constrains to provide durable supports

While there are cultural barriers from the mothers and her families, respondents also described some structural barriers in their workplace, which are more often found in private hospitals setting. Regardless of their knowledge and support of BF practice and TSSB the workload was described by some respondents from clinical staffs as being too much if they are expected to implement it within their current context. They must conduct lactation counselling on top of their current duty, so the workload perceived as overwhelming.

"I work full time at the obstetric clinic .......... have to attend to their clinical problem first such as hyperemesis and then move on to lactation consultation, it takes one to two hours. It is not as easy as telling mothers to breastfeed once the baby is born" (Clinical staff)

The workload problem was admitted by the managers side particularly from from goverment owned services, they had complete trust that their health care fascilities are well equiped. If staffs do not counsel for breasfeeding thus merely due to unintentional forgetfullness because of the high workload not because the staffs do not know what to do or how to do it nor motivated to do so.

\section{The importance of TSSB trainings}

Participants have revealed that he trainings given by the CSO were considered as detailed and practical and help fill the skill and knowledge gap

"The knowledge we received from school were not as detailed as those given in the SAVE training, and then there were practices based on the theory and the results were good, so we are motivated to give information"

(Clinical staff)

Managers found positive changes after the implementation of the TSSB trainings.

"With the implementation of TSSB and IBLC train- ings for our staffs, our exclusive breasfeeding coverage has increased from around 20\% to around $60 \% \ldots .$.

(Manager)

Before the implementation, access to training was considered as an obstacle for many especially on the cost of attending or conducting such training. Therefore, trainings conducted by YSTC were highly valued by respondents since the trainings were also addressing the costing problem. Some health care facilities found ways to address the budget problem by conducting sharing sessions where health care workers who went for TSSB trainings trained their co-worker in their respective health care facilities. Some build systems to ensure the procedure are done properly regardless the gap in skill due to trainings

“....we have a form for that. I made a check list, not all of us are counsellors, I provide them with check list so they can remember and also they can observe if this patient has been taught about position and attachment for example"

(Manager)

Managerial supports as critical factor

Respondents also saw close relationship between inter-professional collaboration and management supports.

“...yes, we do have policy that can be a key for implementation, next is commitment from our colleagues, but the most important role played by the unit manager and the vice manager they are the one who can mobilize their staffs"

(Clinical Staff)

The present of the CSO, YSTC was seen as a necessary push factor for implementation since there were binding contract

"We already have SOP for that, you can see yourself. We have done most of the earlier steps since we became a member of SAVE it was part of the deal and it has already been implemented for two years...."

(Manager)

Respondents have observed many progresses toward TSSB implementation since the CSO intervention was implemented. The trainings that involve not only clinical staffs but also the management personnel seen as very relevant in addressing the barrier they faced. The strict binding contract to not received gift, sponsorship and collaboration with formula milk product also seen as an appropriate to their condition although it was seen as tough at first.

"Initially I was stressed because before I was a counsellor I had received gifts and I had contract (with formula milk) and suddenly I have to commit being a counsellor, it's a big battle for me to safe the future generation or to pursue my own desire" (Clinical staff)

Furthermore, study participants highlighted the need to extend the breastfeeding supports after the mother and baby are out of the care facilities. For home visitation, government owned facilities have better referral 
networking to fill the need gap, however the quality of the services given were not routinely assessed nor they are adequately funded. To increase the coverage of breastfeeding education, repondents from managerial level suggested the stakeholders to extend breasfeeding education to school age girls and also to create TV adds where the grandmoters and mothers alike can easily access the message.

Last but not the least, regarding TSSB elements implementation, respondents also underlined the importance of local legal framework (Perda) that pushes facilities to implement TSSB with clear punishment, this theme also emerged from interviews with health care workers from private health care.

\section{DISCUSSION}

The study has indicated that CSO have played a model an evidence-based practice such as implementation of TSSB trough BFHI. BFHI is a complex, multilevel, evidence-based change process therefore context-focused research implementation models to guide implementation efforts may help identify effective strategies for promoting wider adoption of the BFHI in health services (9).

The study found that the health care workers' knowledge on benefits of breastfeeding and the harm of not giving it, was sound. Interview results also underline that significant portion of the knowledge that they hold are coming from trainings provided by YSTC. Based on health care workers responses, overall the evidence (E) on breastfeeding and TSSB elements (step 3 to 9) implementation was categorized as strong.

The gaps in staff knowledge and skills related to breastfeeding previous to CBO intervention indentified within this study have also been identified in previous studies $(18,23)$ Educating health care staff about breastfeeding has been associated with improved knowledge and attitudes related to breastfeeding, as well as increased rates of in-hospital breastfeeding, mother/ infant skin-to-skin contact, and cup feeding $(24,25)$. However the successes are often context bound esspecially for the continuation of breastfeeding after hospital discharge (26-28). Respondents in this study stated that continuing education on breastfeeding also identified to help health care workers be committed to working through difficulties with breastfeeding, which also has been the case elsewhere (23). Such training done continously and expanded to include not only midwifes and nurses but also pediatricians within the health care system has proven to increase exclusive breastfeeding rate $(29,30)$. Moreover the present of TSSB as a more structured approach in implementing BFHI also cosistent with findings in other countries (31).

Overall, regarding the context of implementation, the study highlight the high cultural context barriers within the community, where grandmothers are considered as an important influence factor esspecially for working mothers. While for structural context barriers for TSSB implementation was considered varied, in which the highest structural contextual barriers experi- enced by private hospital while the lowest by government owned community health centre with government owned hospital was in between.

This cultural context barriers were indentified frequently in other settings, particularly for in family with young working mother (32). It is evident that mothers' knowledge and attitude alone is not sufficient to predict breastfeeding continuation (33). Early termination of breastfeeding was found related to issues such as concerns on lactation difficulties, adequacy infant nutrition and weight; illness or need to take medicine; and the milk pumping problems $(30,34)$. Thus, support for mothers as well as approach to family members to address these issues are also pivotal. This is something that most countries have to deal with in spesific manners Ensuring that all staff receive breastfeeding education has been identified as one way to promote consistency in the breastfeeding messages the mothers get.

Within Indonesian context those messages should also be extended to other family members, especially husbands and grandmothers. In addition, tapping in into health care workers personal experience and wishes may help the process of fostering commitment, in which health care workers are not only seen as delivery agents but also as human with human experiences (35). Therefore TSSB will not be reduced merely as to do list instructions with lack of ownership.

Move to facilitation aspect, the implementation of training by the CSO was considered appropriate due to its ability to address some pressing structural obstacles and provide not only training to improve evidence but also help in addressing other contextual barriers. The CSO has offered opportunities not only for dissemination of evidence-based intervention but also to close gaps on resources provision to attend courses. The CSO also shaped the organizational context and monitored the commitment of managers involved thus ensure higher quality in implementation by erasing formula milk supllementation practice as well as rooming in as a condition to be able to join the program.

However, the role of local stakeholders should not be overlooked for building a more fruitful partnership, as mentioned by respondents on the need of legal framework to push the implementation of the evidence-based practice. Within the course of the CSO intervention in which including advocacy, districts government regulations to support BFHI implementation were enacted. Hence working with the government is feasible and highly encouraged (36). However, stakeholders from the CSO and government side should not neglect the presence of private facilities since they are the one facing the highest structural barriers. Costing exercise as well as cost benefit analysis should also be conducted to assess the current strategy and the scaling up of the trainings to involve more private care practice

Some structural barriers are still unattended for such as increased in workloads which is an unintended consequence of having the knowledge and skill for breastfeeding education, because most often staffs are required to do lactation consultation on top of their regular task. 
Thus addressing the time constrains should also be a takes to solve for management level and this is not uncommon problem even in the developed world setting (37). The lack of higher up breastfeeding champion in health care facilities should also be a concern.

Respondents also stated that the task to maintain breastfeeding is much more difficult than to start it, once the mothers are at home the family support is much more important than the health care workers. Regardless various strategies offered in different health care services to address the problem, agreement on what is best to do is lacking. The present of current peer support trough KP ASI Ekslusif (Exclusive Breasfeeding Support Group) is scatered and often low in funding as well as monitoring and evaluation. Therefore, there is a need for evidence generations to answer the question within Indonesian context. Full commitment from the goverments and other stakeholders will help ensure increase in exclusive breastfeeding continuation (38, 39).

\section{CONCLUSIONS}

The evidence of breastfeeding practice was perceived as strong by the health care workers and the significant proportions of the currently hold knowledge and skill were provided via the CSOs series of trainings. The CSO has offered opportunities not only for dissemination of evidence-based intervention but also to close gaps on resources provision to attend courses. The CSO also shaped the organizational context and monitored the commitment of managers involved thus ensure higher quality in implementation.

Future interventions should foster commitments of health care workers trough increasing the ownership of the program, addressing workload problems, providing more higher up breast-feeding champion as role models with power to move the team and close cooperation with the local government without turning a blind eye to the private sectors involvement. Regarding the TSSB implementation, close attention should be directed to step 10, in which is crucial for exclusive breastfeeding continuation after health care discharge.

\section{Ethics approval and consent to participate}

The study was approved by the ethical committees of University Atmajaya, Jakarta with registration number 1223/III/LPPM-PM.10.05/03/2017. All respondents were consented for their voluntary involvement and received complete oral and written explanations about the process and objectives of the research. The respondents signed an informed consent documents as proof of agreement to participate.

\section{Consent for publication}

Study results are reported in aggregated form thus protecting privacy and personal information of all respondents.

\section{Availability of data and material}

The datasets generated during and/or analysed during the current study are available from the corresponding author on reasonable request.

\section{Disclosure of state of COI}

The authors declare no conflict of interest. The founding sponsors had no role in the design of the study; in the collection, analyses, or interpretation of data; in the writing of the manuscript, and in the decision to publish the results.

\section{Funding}

Financial support was provided by the Ministry of Foreign Affairs of the Netherlands, Grant 24530.

\section{Authors' contributions}

A.S., and E.F. designed the study. E.F. and W.H. conducted the data collection. P.P.J., D.I. and Y.C. conducted analysis. This paper was written by P.P.J., A.S and Y.C. All authors were involved in developing the paper concept and have reviewed and approved the submitted manuscript.

\section{Acknowledgments}

We thank the technical assistance in survey design, implementation, and sample provided by Ravi Menon, Agnes Mallipu (GAIN), Evie Yulianti and Luke Pramudita (YSTC).

\section{REFERENCES}

1) WHO. 2009. Infant and Young Child Feeding; Model Chapter for textbooks for medical students and allied health professionals.

2) Victora CG, Bahl R, Barros AJD, França GVA, Horton S, Krasevec J, et al. 2016. Breastfeeding 1 Breastfeeding in the 21st century: epidemiology, mechanisms, and lifelong eff ect. Lancet 387(10017): 475-490.

3) Jones G, Steketee RW, Black RE, Bhutta ZA, Morris SS, Bellagio Child Survival Study Group. 2003. How many child deaths can we prevent this year? Lancet $\mathbf{3 6 2}$ : 65-71.

4) Hansen K. 2016. Breastfeeding: A smart investment in people and in economies. Lancet 387(10017): 416.

5) Rollins NC, Bhandari N, Hajeebhoy N, Horton S, Lutter CK, Martines JC, et al. 2016. Why invest, and what it will take to improve breastfeeding practices? Lancet 387(10017): 491-504.

6) Labbok M, Taylor E. 2008. Achieving Exclusive Breastfeeding in the United States: Findings and Recommendations. United States Breastfeed Comm 1-55.

7) UNICEF. BABY-FRIENDLY HOSPITAL INITIATIVE Revised Updated and Expanded for Integrated Care SECTION 3 BREASTFEEDING PROMOTION AND SUPPORT IN A BABY-FRIENDLY HOSPITAL A 20-HOUR COURSE FOR MATERNITY STAFF. 2009.

8) Abrahams SW, Labbok MH. 2009. Exploring the impact of the Baby-Friendly Hospital Initiative on trends in exclusive breastfeeding. Int Breastfeed J 4: 11.

9) Moore T, Gauld R, Williams S. 2007. Implementing Baby Friendly Hospital Initiative policy: The case of New Zealand public hospitals. Int Breastfeed J 2(1): 8.

10) Ojofeitimi EO, Esimai OA, Olaobaju OF, Olanuga TO. 2000. Breast Feeding Practices in Urban and Rural Health Centres: Impact of Baby Friendly Hospital Initia- 
tive in Ile-Ife, Nigeria. Nutr Health 14: 119-125.

11) Kementrian Kesehatan RI. 2017. Profil Kesehatan Indonesia 2016.

12) Marzuki NS, Yohmi E, Nainggolan E, Hegar B, Oswari H, Ayu G, et al. 2014. Breastfeeding practices in mothers: a qualitative study. Paediatr Indones 54(1): 35-41.

13) Bryant J, Bonevski B, Paul C. 2011. A survey of smoking prevalence and interest in quitting among social and community service organisation clients in Australia: A unique opportunity for reaching the disadvantaged. BMC Public Health 11: 827.

14) Wilson MG, Lavis JN, Guta A. 2012. Community-based organizations in the health sector: A scoping review. Heal Res Policy Syst 10(1): 1.

15) Frisdiantiny E. Documentation of Baby-Friendly Health Facility Initiative Malang and Sidoarjo, East Java, Indonesia 2014-2016 “an. 2017.

16) Semenic S, Childerhose JE, Lauzière J, Groleau D. 2012. Barriers, facilitators, and recommendations related to implementing the Baby-Friendly initiative (BFI): An integrative review. J Hum Lact 28(3): 317-334.

17) Stetler CB, Damschroder LJ, Helfrich CD, Hagedorn HJ. 2011. A Guide for applying a revised version of the PARIHS framework for implementation. Implement Sci 6(1): 99.

18) Taylor C, Gribble K, Sheehan A, Schmied V, Dykes F. 2011. Staff perceptions and experiences of implementing the Baby Friendly Initiative in neonatal intensive care units in Australia. J Obstet Gynecol Neonatal Nurs 40(1): 25-34.

19) Benoit B, Semenic S, Benoit B. 2014. Barriers and facilitators to implementing the Baby-Friendly hospital initiative in neonatal intensive care units. J Obstet Gynecol Neonatal Nurs 43: 614-624.

20) Kitson AL, Rycroft-Malone J, Harvey G, McCormack B, Seers K, Titchen A. 2008. Evaluating the successful implementation of evidence into practice using the PARiHS framework: Theoretical and practical challenges. Implement Sci 3(1): 1-12.

21) Elo S, Kyngäs H. 2008. The qualitative content analysis process. J Adv Nurs 62: 107-115.

22) Harvey G, Kitson A, McCormack B, Rycroft-Malone J, Seers K, Titchen A. 2004. An exploration of the factors that influence the implementation of evidence into practice. J Clin Nurs 13(8): 913-924.

23) Cricco-Lizza R. 2016. Infant Feeding Beliefs and Day-toDay Feeding Practices of NICU Nurses. J Pediatr Nurs 31(2): e91-e98.

24) Carvalho P, Jesus D, Inês M, Oliveira C De, Costa S. 2016. Impact of health professional training in breastfeeding on their knowledge, skills, and hospital practices: a systematic review. J Pediatr (Rio J) 92(5): 436450 .

25) Li CM, Li R, Ashley CG, Smiley JM, Cohen JH, Dee DL. 2014. Associations of hospital staff training and policies with early breastfeeding practices. J Hum Lact 30(1): 88-96.

26) Bonet M, Forcella E, Blondel B, Draper ES, Agostino R, Cuttini M, et al. 2015. Approaches to supporting lactation and breastfeeding for very preterm infants in the
NICU: A qualitative study in three European regions. BMJ Open 5(6): 1-10.

27) Zakarija-Grković I, Šegvić O, Božinović T, Ćuže A, Lozančić T, Vučković A, et al. 2012. Hospital practices and breastfeeding rates before and after the UNICEF/ WHO 20-hour course for maternity staff. J Hum Lact 28(3): 389-399.

28) Yotebieng M, Labbok M, Soeters HM, Chalachala JL, Lapika B, Vitta BS, et al. 2015. Ten Steps to Successful breastfeeding programme to promote early initiation and exclusive breastfeeding in DR Congo: A cluster-randomised controlled trial. Lancet Glob Heal 3(9): e546e555.

29) Coutinho SB, Lira PIC, Lima MC, Frias PG, Eickmann SH, Ashworth A. 2014. Promotion of exclusive breastfeeding at scale within routine health services: Impact of breast-feeding counselling training for community health workers in Recife, Brazil. Public Health Nutr 17(4): 948-955.

30) S, Resnik A, Paige D. 2012. Long-term breastfeeding support: Failing mothers in need. Matern Child Health J 16(9): 1926-1932.

31) Beake S, Pellowe C, Dykes F, Schmied V, Bick D. 2012. A systematic review of structured compared with non-structured breastfeeding programmes to support the initiation and duration of exclusive and any breastfeeding in acute and primary health care settings. Matern Child Nutr 8(2): 141-161.

32) Yotebieng M, Chalachala JL, Labbok M, Behets F. 2013. Infant feeding practices and determinants of poor breastfeeding behavior in Kinshasa, Democratic Republic of Congo: A descriptive study. Int Breastfeed J 8(1): $1-9$.

33) Ishak S, Adzan NAM, Quan LK, Shafie MH, Rani NA, Ramli KG. 2014. Knowledge and beliefs about breastfeeding are not determinants for successful breastfeeding. Breastfeed Med 9(6): 308-312.

34) Odom EC, Li R, Scanlon KS, Perrine CG, GrummerStrawn L. 2013. Reasons for earlier than desired cessation of breastfeeding. Pediatrics 131(3): e726-e732.

35) Thomson G, Bilson A, Dykes F. 2012. Implementing the WHO/UNICEF Baby Friendly Initiative in the community: A "hearts and minds" approach. Midwifery 28(2): 258-264.

36) Steffek J, 2013. Explaining cooperation between IGOs and NGOs-push factors, pull factors, and the policy cycle. Review of International Studies 39: 993-1013.

37) Schmied V, Gribble K, Sheehan A, Taylor C, Dykes FC. 2011. Ten steps or climbing a mountain: A study of Australian health professionals' perceptions of implementing the baby friendly health initiative to protect, promote and support breastfeeding. BMC Health Serv Res 11: 208.

38) Model G, Pérez-escamilla R, Curry L, Minhas D, Taylor L, Bradley E. 2015. Scaling up of breastfeeding promotion programs in low- and middle-income countries. Adv Nutr 3(3): 790-800.

39) Saadeh RJ. 2012. The Baby-Friendly hospital initiative 20 years on: Facts, progress, and the way forward. $J$ Hum Lact 28(3): 272-275. 